\title{
Ocular dominance, reading, and spelling ability in schoolchildren
}

\author{
S P NEWMAN, J F WADSWORTH, R ARCHER, AND R HOCKLY \\ From the Academic Department of Psychiatry, Middlesex Hospital Medical School, London, \\ and Guy's Hospital, London
}

SUMMARY The association of reading disability with perceptuomotor problems has had a chequered history. This study examines the relationship between a new test of ocular dominance and reading and spelling ability in a group of 298 schoolchildren. Similar rates for unstable ocular dominance were found for poor readers as in comparable studies. The rates of unstable ocular dominance did not differ between the 'dyslexics' and the controls. These findings in a blind study question the role of this test as a diagnosis of 'dyslexia.'

A number of studies of children with reading disabilities have suggested that they suffer from a perceptuomotor problem. In particular an association has been claimed between difficulties in sequential eye movements while following a series of light emitting diodes and reading disability. ${ }^{12}$ More recently, however, a number of studies have failed to support the original contentions. ${ }^{34}$ Furthermore there is some suggestion that the ability to track sequentially displayed lights is dependent on reading skill and the direction in which text has been read. ${ }^{5}$

The association of reading disability and a failure to establish a dominant eye has had a chequered history. Benton and his colleagues claimed to have found support for an association between unfixed ocular dominance and reading disability, but withdrew their claims in the light of contradictory research and their failure to show an association between improvement in reading and the development of dominance following eye occlusion. ${ }^{6-8}$ More recently Stein and Fowler have reported an association between a new test of ocular dominance and reading disability which they suggest may account for the erratic eye movements some studies have found with 'dyslexics." They argue that 'dyslexia' may be associated with a failure to establish ocular dominance because it may lead to 'confusion about precisely where words and letters are positioned on a page.' These authors examined in detail 80 children who had been referred with reading problems to the

Correspondence to Dr S P Newman,/Academic Department of Psychiatry, Middlesex Hospital Medical School, Mortimer Street, London W1P 8AA.
Ophthalmology Department of the Royal Berkshire Hospital and found $63 \%$ of them to have unstable ocular dominance as determined by a modified Dunlop test. This form of assessment of ocular dominance is of the sensory variety, where some degree of conflict exists between the information transmitted to each eye. This type of ocular dominance test, in contrast to monocular sighting preference/dominance or acuity dominance, has received relatively little attention in the literature on reading disability.

The study reported in this paper re-examines the association between the test of ocular dominance used by Stein and Fowler and reading ability in schoolchildren where detailed information of the child's reading, spelling, and intellectual abilities were also gathered. The definition of 'dyslexia' is complicated, and we have followed Stein and Fowler in specifying reading and spelling ability in relation to chronological age. The group considered to be dyslexic are those who produce a reading or spelling performance at least 18 months behind their chronological age. In addition, in this study the measures of ocular dominance were all conducted in the absence of the examiner's (RH) having any knowledge of the child's reading or intellectual abilities.

\section{Subjects and methods}

The subjects consisted of 298 children aged 7-11 from various schools selected to participate in a larger study of reading. None of the children had been referred to any clinic for reading difficulties and 
none had any gross neurological defecit. The information gathered on each child consisted of a full intellectual assessment (WISC) and three reading tests to examine three levels of reading skill. The Schonell graded word spelling test was used to assess the ability to spell to dictation. The Schonell graded word reading test was used to examine the child's ability to read single words in isolation, and the Neale test provided a measure of accuracy in reading prose passages. Each of these tests yields a score which is then converted into a reading or spelling age. As is common in studies of 'dyslexia', no child was selected who had either a verbal or performance IQ of less than 90 .

These tests were all conducted by a psychologist.

\section{DUNLOP TEST}

The test of ocular dominance used in this study was identical to that used by Stein and Fowler. This involves the child viewing two macular fusion slides through a synoptophore. The slide viewed by the right eye has a house with a small tree to the left of the front door, while in that viewed by the left eye a large tree appeared to the right of the door of the house. The trees were thus initially projected to the nasal retina of each eye. The subject adjusted a knob until the two slides were found to fuse. The subject then perceived a house with a small tree to the left (viewed by the right eye) and a large tree to the right of the door (viewed by the left eye). The tubes of the synoptophore were then separated and the subject's eyes diverged to retain fusion. The relationship of the trees to the house remained constant in each slide, but the subject gained a strong impression that one of the trees had moved. This test enables the eye whose ocular motor and retinal signals are associated to be identified and thus the dominant eye to be distinguished. In order to prevent the child from adopting a guessing strategy the slides were changed throughout the test. To ensure that a comparison would be possible with the other data relating this test to reading, the orthoptist conducting the examination was trained by Stein and Fowler.

The test was repeated 10 times, and the convention of scoring adopted by Stein and Fowler and followed in this paper is that if the dominant eye is located on the same side on eight or more occasions then the child is considered to have a fixed dominant eye. With scores of less than eight the child is considered to have unstable or unfixed dominance.

\section{Results}

1. Left and right eye, dominance. The number of subjects showing fixed right eye dominance $(n=99)$ was significantly greater than the number showing left ocular dominance $(n=52)$. This finding is consistent with other assessments of sensory dominance and, in fact, sighting preference/dominance. ${ }^{10}$

2. Eye dominance and spelling ability. It may be expected that spelling ability, with its requirement to resolve small spatial positions, would be the most sensitive reading index of any problems of ocular dominance. ${ }^{10}$ The results shown in Figure 1 indicate the percentage of children with fixed and unfixed ocular dominance at various levels of spelling ability. Those with a spelling age of 18 months or more behind their chronological age would be classed as having specific spelling difficulties and would be expected to indicate a significantly smaller proportion of individuals with fixed ocular dominance. In contrast those whose spelling is advanced significantly above their chronological age would be expected to have a greater proportion of fixed dominance. Although the trend in these findings was in the direction predicted, the differences between groups was small and did not reach significance $\left(\chi^{2}=2.74 ; 3\right.$ df; $p>0.05$ ). It is also worth noting that $37 \%$ of children with excellent spelling failed to show fixed ocular dominance.

The difference between the fixed and unfixed groups at each of the levels of spelling performance relative to chronological age displayed in Figure 1 were further examined by means of $t$ tests. The groups were compared on verbal IQ, performance IQ, and age. The $t$ tests failed to show any differences between the fixed and unfixed groups on either IQ measure. With the exception of one group, all the comparisons on age failed to indicate any significant differences. The exception was with the group whose spelling ability was 18 months ahead of their chrono-

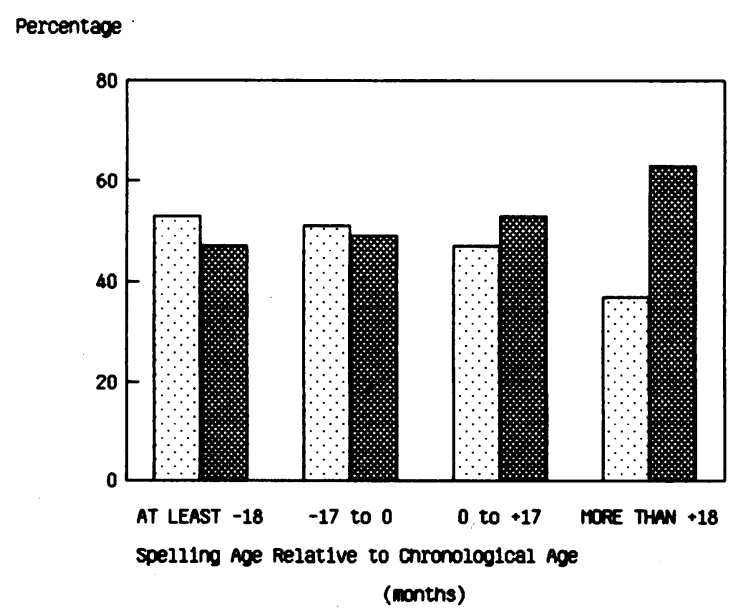

Fig. 1 Ocular dominance and spelling. Unfixed: $<8$ trials indicating one eye dominant. Fixed: 8-10 trials indicating one eye dominant. 
Percentage

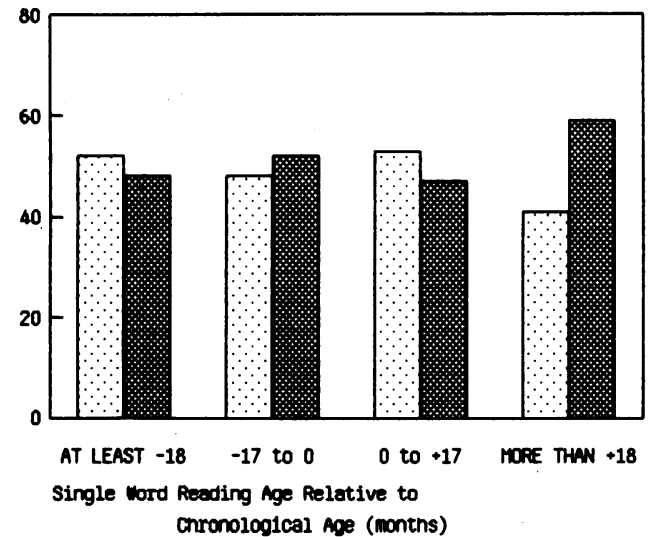

Fig. 2 Ocular dominance and single word reading. Unfixed: $<8$ trials indicating one eye dominant. . Fixed: 8-10 trials indicating one eye dominant.

logical age $(t=2 \cdot 06 ; \mathrm{df} 28 ; \mathrm{p}<0 \cdot 05)$. The mean age for those with fixed ocular dominance was five months less than those with unfixed dominance.

3. Eye dominance and single word reading. A similar analysis to that performed on the spelling data was conducted on the data for single word reading. These results are displayed in Figure 2. They fail to show any association between ocular dominance and difficulties in reading single words $\left(\chi^{2}=1.75\right.$; df 3 ; $\mathrm{p}>0.05$ ).

Further analysis of the fixed and unfixed groups at each of the levels of performance of single word reading shown in Figure 2 failed to indicate any differences between their verbal IQ, performance IQ, and age.

Percentage

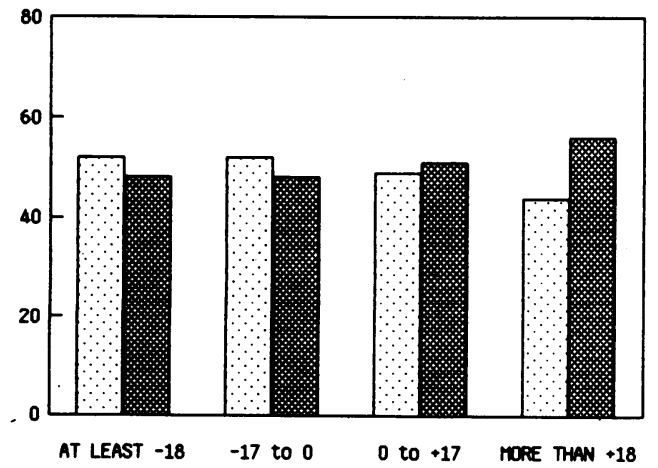

Neale Accurracy Age and Chronological Age (nonths)

Fig. 3 Ocular dominance and reading prose passages. $\square$ Unfixed: <8 trials indicating one eye dominant. Fixed: 8-10 trials indicating one eye dominant.
4. Eye dominance and reading prose passages. The analysis of the data from reading prose passages is shown in Figure 3 . This analysis failed to show any significant association between reading prose passages and ocular dominance $\left(\chi^{2}=0.99 ;\right.$ df 3 ; p $>0.05$ ). $51 \%$ of the poor readers on this test failed to indicate fixed ocular dominance, while $44 \%$ of those who performed excellently on this test also indicated a lack of fixed ocular dominance.

The verbal IQ, performance IQ, and age of the fixed and unfixed ocular dominance groups were compared at each of the levels of reading prose passages relative to chronological age. With one exception these analyses failed to indicate any significant difference between these groups on these variables. The group who had unfixed ocular dominance and were 18 months behind their chronological age on the Neale test had a significantly higher performance IQ than those at the same level of reading performance with fixed ocular dominance.

5. Eye dominance and intelligence. A separate analysis was conducted to examine the relationship between ocular dominance and the two measures of intelligence. No significant differences were found between the proportion of fixed and unfixed individuals when the subjects were divided into three bands of IQ scores. These results are shown in Figures 4 and 5.

\section{Discussion}

The above data fail to confirm any association between this test of ocular dominance and spelling,

Percentage

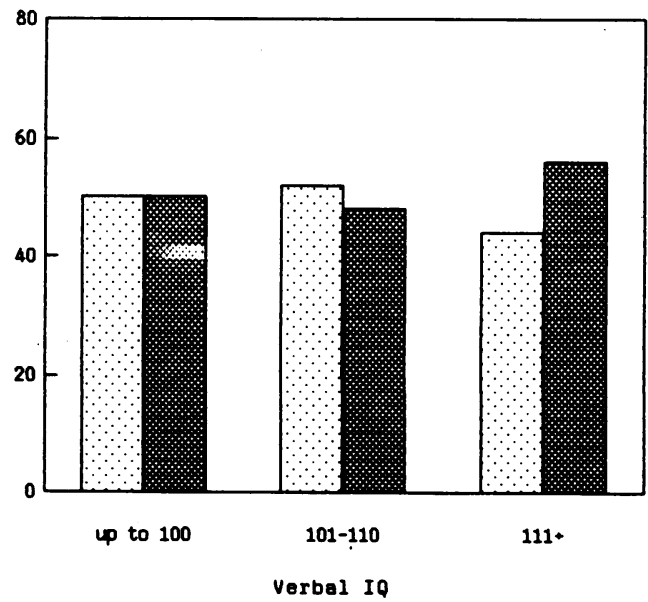

Fig. 4 Performance IQ and ocular dominance. $\square$ Unfixed: $<8$ trials indicating one eye dominant. Fixed: 8-10 trials indicating one eye dominant. 
Percentage

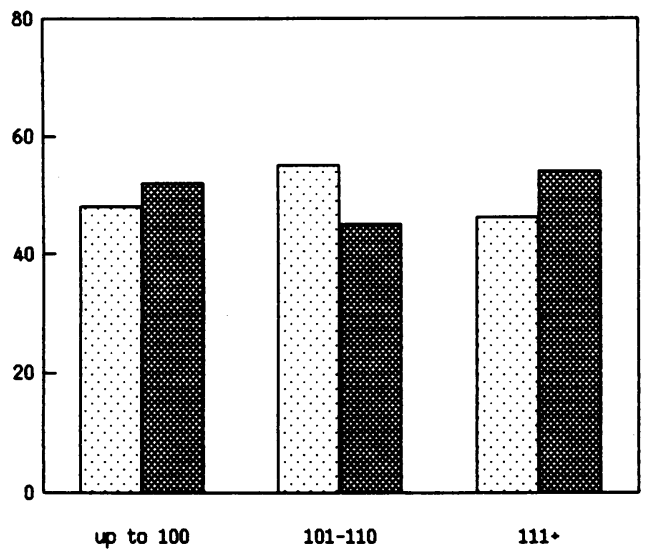

Performence IQ

Fig. 5 Verbal IQ and ocular dominance. $\square$ Unfixed: $<8$ trials indicating one eye dominant. Fixed: 8-10 trials indicating one eye dominant.

reading single words, and reading prose passages. The only suggestion of an association concerned the spelling test, but this failed to reach significance. In addition no significant tendency for fixed ocular dominance was found with increasing verbal or performance IQ. The detailed analysis of IQ and age at each level of reading and spelling performance failed to show any significant effects of these variable with fixed and unfixed ocular dominance.

In comparing our results with those of Stein and Fowler, it is important to point out that we are not in disagreement over the proportion of 'dyslexic' subjects who fail to establish fixed ocular dominance. They report data on two groups of 'dyslexics' who yielded $63 \%$ and $52 \%$ with unfixed ocular dominance. We found $54 \%, 52 \%$, and $52 \%$ of individuals 18 months behind their chronological age on spelling, reading single words, and reading prose passages respectively, to have unfixed ocular dominance. Stein and Fowler report finding only 1 out of 80 of their normal subjects to have unstable ocular dominance. The findings reported above indicate that the proportion of individuals with fixed and unfixed ocular dominance do not differ according to spelling and reading ability. In fact a sizeable proportion of individuals who are particularly adept at these tasks still fail to indicate a stable ocular dominance on the test used by Stein and Fowler.

The most significant difference between our study and that performed by Stein and Fowler, which may go some way to account for the disparity of results, is that in this study the subjects were all examined by an orthoptist who had no knowledge of the child's per- formance on any of the other measures. In Stein and Fowler's study the 'dyslexic' children had been referred to a reading clinic and/or the ophthalmology department for reading problems. The 'normal' readers were selected from schools and matched to a subgroup of the 'dyslexics.' It appears that the testing was performed on different occasions and thus it is unlikely that it was performed blind.

In the present study the subjects were all selected from normal schools and the 'dyslexic' group was not restricted to those referred for either assessment or treatment. This difference does not appear to have significantly influenced the results, as in both studies the percentage of 'dyslexics' with unstable ocular dominance remained approximately the same.

The test of ocular dominance used in this study was the same as that in the Stein and Fowler study. Because the orthoptist's examination and the modified Dunlop test are difficult to perform and we wished to have our results comparable with those in their study, our orthoptist (RH) spent a period of time being trained by Fowler. Both were satisfied at the end of this training that the techniques of assessment were comparable.

We conclude on the basis of our study that ocular dominance as assessed by this version of the Dunlop test does not on its own have any direct relationship to reading and spelling performance of schoolchildren. In particular it does not discriminate between those who perform poorly and those with adequate or superior performance. We are currently analysing other measures of oculomotor and perceptual functioning in these subjects, and it is possible that a combination of unfixed ocular dominance and some other function may lead to reading difficulties.

We thank Dr John Stein and Sue Fowler for their assistance and advice as well as the time in training our orthoptist. We thank all the schools whose co-operation made this study possible. We also acknowledge the generous support of the Linbury Trust.

This research was supported by a generous grant from the Linbury Trust.

\section{References}

1 Pavlides G. Dyslexic's erratic eye movements. Dyslexia Rev 1978; 1: 22-8.

2 Pavlides G. The 'dyslexia syndrome' and its objective diagnosis by erratic eye movements. In: Rayner K, ed. Eye movements in reading. New York: Academic Press, 1983.

3 Stanley G, Smith G, Hewell E. Eye-movements and sequential tracking in dyslexic and control children. Br J Psychol 1983; 73: 181-7.

4 Olsen R, Kliegel R, Davidson B. Dyslexic and normal reader's eye movements. J Exp Psychol 1983; 9: 816-25.

5 Newman SP, Civil M. Directional differences in eye tracking. Paper presented at the Second European Conference on Eye Movements, Nottingham, England. 1983.

6 Benton CD, McCann JW, Larsen M. Dyslexia and dominance.J Pediatr Ophthalmol 1965; 2: 53-7. 
7 Benton CD, McCann JW, Larsen M. A practical approach for the ophthalmologist. J Pediatr Ophthalmol 1968; 5: 25-9.

8 Benton CD, McCann JW. Dyslexia and dominance. J Pediatr Ophthalmol 1969; 6: 220-2.
9 Stein JF, Fowler S. Diagnosis of 'dyslexia' by means of a new indicator of eye dominance. Br J Ophthalmol 1982; 66: 332-6.

10 Porac V, Coren S. The dominant eye. Psychol Bull 1976; 83: 880-97. 